\title{
Effect of beta blockade on exercise response after cardiac transplantation
}

\author{
RODNEY S BEXTON, „ JOHN R MILNE, RICHARD CORY-PEARCE, $\dagger$ \\ TERENCE A H ENGLISH, A JOHN CAMM‡
}

From Department of Cardiology, St Bartholomew's Hospital, West Smithfield, London; and British Heart Foundation Heart Transplant Research Unit, Papworth Hospital, Papworth Everard, Cambridge

SUMMARY Six cardiac transplant recipients underwent maximal exercise testing before and after the administration of intravenous propranolol to assess the effect of beta blockade on their exercise heart rate response and exercise capacity. Before propranolol the patients were capable of a mean of 6.8 minutes of exercise and heart rate increased from a resting value of $102 \pm 25$ a minute to $138 \pm 34$ at peak exercise-a mean increase of $35 \%$. All tests were terminated because of tiredness or muscle weakness. After one hour's rest, intravenous propranolol $(0.2 \mathrm{mg} / \mathrm{kg}$ over $10 \mathrm{minutes})$ was administered with a reduction in resting heart rate from $109 \pm 28$ a minute to $83 \pm 16$. During the repeat exercise test the patients were capable of a mean of 4.5 minutes of exercise and all tests were terminated by extreme exhaustion and/or unsteadiness requiring immediate cessation of the treadmill. Heart rate increased from a resting value of $83 \pm 16$ a minute to $96 \pm 18$ at peak exercise.

The exercise capability of the denervated heart is conspicuously reduced by beta blockade, presumably because of its reliance on circulating catecholamines.

Although reinnervation of the transplanted heart has been well documented after orthotopic transplantation of the canine heart, ${ }^{12}$ the transplanted human heart appears to remain both functionally and anatomically denervated indefinitely. ${ }^{34}$ In the absence of the normal cardioacceleratory sympathetic stimulation of exercise, the exercise heart rate response of the denervated heart is gradual and delayed both in onset and offset..$^{5-7}$ Haemodynamic studies, however, both in animals 589 and in $\operatorname{man}^{367}$ have indicated that denervation neither reduces the capacity for exercise nor the associated increase in cardiac output. In the denervated heart the increase in cardiac output is initially mediated by an increase in stroke volume ${ }^{368}$ through the Frank-Starling mechanism, ${ }^{1011}$ and only later, with severe exercise, does an increase in heart rate and contractility contribute, associated with increases in the levels of circulating catecholamines. ${ }^{6} 12$

Studies on the effect of beta blockade on the exer-

\footnotetext{
^Recipient of British Heart Foundation Fellowship. †British Heart Foundation Senior Research Fellow. $¥$ Wellcome Senior Lecturer.
}

Accepted for publication 15 February 1983 cise capacity in intact man have produced conflicting results ${ }^{13-18}$ though in the majority of studies maximal work capacity was not significantly reduced. Theoretically beta blockade should significantly reduce the maximal exercise capacity of the denervated heart, with its reliance on circulating catecholamines. Though limited studies have been performed in denervated ${ }^{1920}$ and isolated ${ }^{19}$ canine hearts, no study on the effect of beta blockade on the exercise response of human cardiac transplant recipients has been reported.

\section{Patients and methods}

Six cardiac transplant recipients underwent investigation seven to 18 (mean 13) months after transplantation. Their ages ranged from 28 to 53 (mean 40 ) years and five were men and one was a women (Table 1). All patients were functionally well with no haematologi- $\stackrel{\mathscr{Q}}{?}$ cal, biochemical, or electrocardiographic evidence of rejection. All patients were taking prednisolone and azathioprine as routine immunosuppressive therapy. No patient was taking cardioactive drugs. Written informed consent was obtained from each patient before beginning the study. 
Table 1 Individual patient data

\begin{tabular}{lllll}
\hline Case No. & $\begin{array}{l}\text { Age } \\
(y)\end{array}$ & Sex & $\begin{array}{l}\text { Pre-transplant } \\
\text { diagnosis }\end{array}$ & $\begin{array}{l}\text { Time of study } \\
\text { (months postop) }\end{array}$ \\
\hline 1 & 34 & F & CM & 8 \\
2 & 28 & M & CAD & 14 \\
3 & 49 & M & CAD & 18 \\
4 & 35 & CAD & CAD & 17 \\
5 & 53 & M & CAD & 15 \\
6 & 42 & M & CAD & 7 \\
\hline
\end{tabular}

$\mathrm{CM}$, cardiomyopathy; CAD, coronary artery disease.

Before starting the exercise tests a standard 12 lead electrocardiogram was recorded to ascertain the most suitable six leads for recording during exercise. After orientation to the equipment, the patients underwent maximal graded exercise testing using a Quinton treadmill» and a standard Bruce protocol. ${ }^{21}$ At one minute intervals six leads of electrocardiogram were recorded at a paper speed of $50 \mathrm{~mm} / \mathrm{s}$. The blood pressure was also measured at three minute intervals. The patients were exercised until forced to stop by a subjective endpoint such as fatigue, exhaustion, dyspnoea, or muscle weakness. Electrocardiographic recordings were continued at one minute intervals after the cessation of exercise until the heart rate had returned to within $5 \%$ of the pre-exercise resting rate.

After approximately a one hour rest, intravenous propranolol $(0.2 \mathrm{mg} / \mathrm{kg})$ was administered over 10 minutes with electrocardiogram and blood pressure recordings at one minute intervals. The repeat exercise test was started five minutes after completion of the injection. The patients were again maximally exercised with electrocardiographic and blood pressure recordings as previously.

\section{STATISTICAL ANALYSIS}

Results are presented as the mean value \pm one standard deviation from the mean, and the Student's two-tailed $t$ test for paired data was used to determine probable differences, which were considered significant when $\mathrm{p}<0.05$.

\section{Results}

Before the initial exercise test the resting heart rates ranged from 62 to $138(102 \pm 25) \mathrm{bpm}$ and the resting blood pressure was $134 \pm 27 / 88 \pm 16 \mathrm{mmHg}$. The patients were capable of from five to eight $(6 \cdot 8 \pm 1 \cdot 2)$ minutes of exercise and all tests were terminated by tiredness or muscle weakness. Increases in heart rate from resting to peak exercise ranged from 16 to 57 $(36 \pm 14)$ bpm with peak exercise heart rates of 88 to $178(138 \pm 34) \mathrm{bpm}$ (Fig. 1). Expressed as a percentage

\footnotetext{
„Quinton Instruments Company Limited, Seattle, Washington.
}

control

口 propranolol

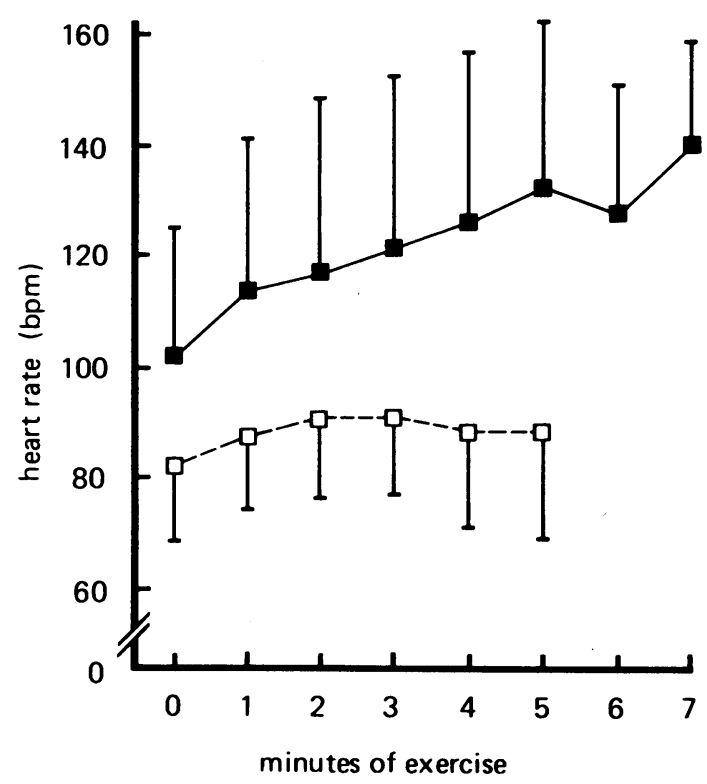

Fig. 1 Absolute heart rate (mean $\pm 1 S D$ ) for each minute of exercise before and after the administration of propranolol. bpm, beats per minute.

of the resting heart rate the increases varied from $17 \%$ to $56 \%$, with a mean of $35 \%$. After three minutes of exercise the heart rate had increased by $16 \%$ with a further $19 \%$ increase over the remaining minutes of exercise (Fig. 2). Both systolic and diastolic blood pressure rose slightly during exercise, though not significantly, to $148 \pm 29 / 90 \pm 17 \mathrm{mmHg}$. The time required to regain control heart rate varied from 12 to 22 (mean 18) minutes.

The administration of propranolol resulted in a reduction in resting heart rate from $109 \pm 28 \mathrm{bpm}$ to $83 \pm 16 \mathrm{bpm}(\mathrm{p}<0.01)$ and in blood pressure from $125 \pm 30 / 78 \pm 12 \mathrm{mmHg}$ to $105 \pm 15 / 75 \pm 15 \mathrm{mmHg}$ (not significant).

During the repeat exercise test the patients were capable of from 2.75 to 6 minutes of exercise $(4.5 \pm 1 \cdot 1$ minutes; $p<0.01$ compared with control exercise test). On this occasion, however, the endpoint of the test was dramatically sudden with all but one of the patients developing pronounced unsteadiness which required immediate cessation of the treadmill to prevent them falling off. None of these patients would have been capable of further exercise. Recovery, however, took place quickly after the termination of exercise. Increases in heart rate ranged from 5 to $25 \mathrm{bpm}$ (13 $\pm 9 \mathrm{bpm} ; \mathrm{p}<0.01$ compared with control exercise 
Table 2 Individual patient results

\begin{tabular}{|c|c|c|c|c|c|c|c|c|c|c|}
\hline \multirow[t]{2}{*}{ Case No. } & \multicolumn{2}{|c|}{$\begin{array}{l}\text { Resting } \\
H R(b p m)\end{array}$} & \multicolumn{2}{|c|}{$\begin{array}{l}\text { Peak exercise } \\
H R(b p m)\end{array}$} & \multicolumn{2}{|c|}{$\begin{array}{l}\text { Increase in } \\
H R(b p m)\end{array}$} & \multicolumn{2}{|c|}{$\begin{array}{l}\% \text { increase in } \\
H R\end{array}$} & \multicolumn{2}{|c|}{$\begin{array}{l}\text { Exercise duration } \\
(\min )\end{array}$} \\
\hline & $C$ & Prop & $C$ & Prop & $C$ & Prop & $C$ & Prop & $C$ & Prop \\
\hline $\begin{array}{l}1 \\
2 \\
3 \\
4 \\
5 \\
6\end{array}$ & $\begin{array}{r}62 \\
92 \\
138 \\
112 \\
102 \\
109\end{array}$ & $\begin{array}{r}56 \\
84 \\
104 \\
94 \\
81 \\
79\end{array}$ & $\begin{array}{r}88 \\
108 \\
178 \\
147 \\
159 \\
149\end{array}$ & $\begin{array}{r}62 \\
89 \\
109 \\
107 \\
103 \\
104\end{array}$ & $\begin{array}{l}26 \\
16 \\
40 \\
35 \\
57 \\
40\end{array}$ & $\begin{array}{r}6 \\
5 \\
5 \\
13 \\
22 \\
25\end{array}$ & $\begin{array}{l}42 \\
17 \\
29 \\
31 \\
56 \\
37\end{array}$ & $\begin{array}{r}11 \\
6 \\
5 \\
14 \\
27 \\
32\end{array}$ & $\begin{array}{l}6 \\
8 \\
5 \\
8 \\
7 \\
7\end{array}$ & $\begin{array}{l}6 \\
4.5 \\
2.75 \\
4.5 \\
4.5 \\
5\end{array}$ \\
\hline $\begin{array}{l}\text { Mean } \\
\pm 1 \text { SD }\end{array}$ & $\begin{array}{r}102 \\
25\end{array}$ & $\begin{array}{l}83 \\
16\end{array}$ & $\begin{array}{r}138 \\
34\end{array}$ & $\begin{array}{l}96 \\
18\end{array}$ & $\begin{array}{l}36 \\
14\end{array}$ & $\begin{array}{r}13 \\
9\end{array}$ & $\begin{array}{l}35 \\
13\end{array}$ & $\begin{array}{l}16 \\
11\end{array}$ & $\begin{array}{l}6.8 \\
1.2\end{array}$ & $\begin{array}{l}4.5 \\
1 \cdot 1\end{array}$ \\
\hline $\mathrm{p}$ & \multicolumn{2}{|c|}{$<0.01$} & \multicolumn{2}{|c|}{$<0.01$} & \multicolumn{2}{|c|}{$<0.01$} & \multicolumn{2}{|c|}{$<0.01$} & \multicolumn{2}{|c|}{$<0.01$} \\
\hline
\end{tabular}

HR, heart rate; bpm, beats/min; min, minutes; C, control; Prop, propranolol; SD, standard deviation; p, p value (Student's two-tailed t test fote paired data), propranolol vs control.

test), with peak exercise heart rates of 62 to 109 $(96 \pm 18) \mathrm{bpm}$ (Fig. 1). The percentage increase in heart rate ranged from 5 to $32 \%$ with a mean increase of $16 \%(\mathrm{p}<0.01$ compared with control exercise test $)$. The heart rate had increased by $12 \%$ after three minutes of exercise with little or no increase after this time (Fig. 2). There was again no significant change in blood pressure during the period of exercise.

Table 2 summarises the individual and the overall results and Fig. 3 illustrates typical electrocardiographic recordings during an exercise test before and after propranolol.

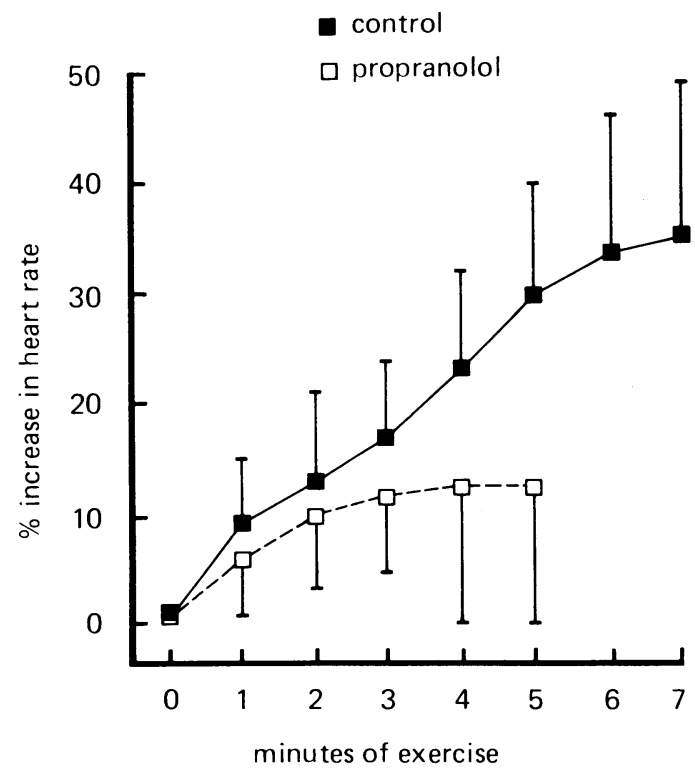

Fig. 2 Percentage increase in heart rate (expressed as a percentage of the resting heart rate) for each minute of exercise before and after the administration of propranolol.

\section{Discussion}

The physiology of exercise of the denervated heart has been extensively studied both in dogs 5891920 and i humans. ${ }^{3671222}$ Though the heart rate response of the denervated heart to graduated exercise is delayedog
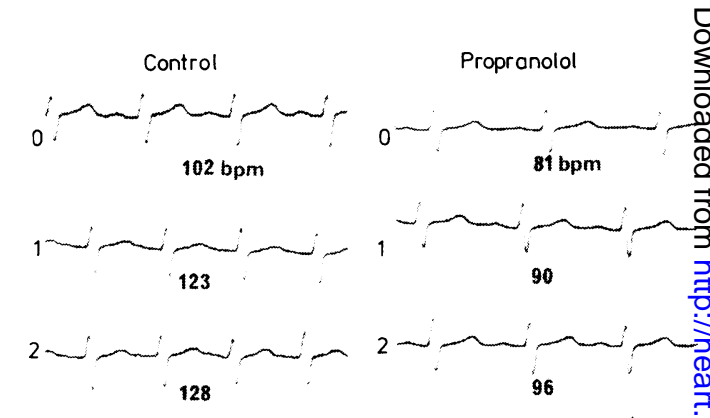

مـ (131)

旁 4

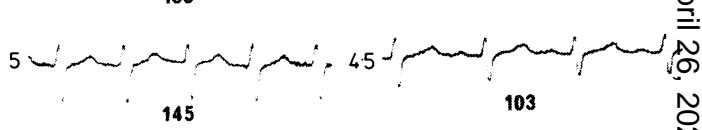

6 Hon

155

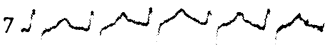

159

Fig. 3 Typical electrocardiographic recordings during an exercise test before and after propranolol. The heart rate for each minute of exercise is indicated. bpm, beats per minute. 
gradual, and reduced ${ }^{5-7}$ there is no impairment of either exercise capacity or augmentation of cardiac output and oxygen consumption. ${ }^{356}$ Early in exercise the pattern of response of the denervated heart is, however, almost the complete opposite to that of the innervated heart. The innervated heart responds to exercise with an almost immediate increase in heart rate with little or no increase in stroke volume, 8922 the Frank-Starling mechanism only being important with severe exertion. ${ }^{23}{ }^{24}$ In the denervated heart in early, and with mild, exercise there is little change in heart rate. The increase in cardiac output is almost entirely mediated through an increase in stroke volume as a result of increased venous return, augmented preload, and the Frank-Starling mechanism. ${ }^{368}$ Haemodynamic studies have shown a pronounced increase in left ventricular end-diastolic pressure ${ }^{3}$ and volume $^{6}$ associated with this increase in stroke volume in human transplant recipients. Later, and with more severe exercise, increase in heart rate tends to be more pronounced and, together with an increase in contractility, plays an important role in augmenting cardiac output. 5622

The time course of the exercise response of the transplanted heart to severe exercise suggests a humoral mechanism. Normal subjects have been shown to increase plasma catecholamine levels during exercise $^{2526}$ with the most pronounced increases occurring during maximal exercise. Similarly, Pope et al. ${ }^{6}$ have shown a dramatic increase in plasma noradrenaline levels in transplant recipients with the onset of severe exercise which correlated very closely with the increase in heart rate and velocity of circumferential fibre shortening.

Although circulating catecholamines appear to account for the increase in heart rate and contractility occurring with severe exercise in transplant patients, various theories have been proposed to account for the slight increase in heart rate occurring in early, and with mild, exercise. Studies in denervated dogs have shown that this increase is not related to an increase in intravascular temperature ${ }^{5}$ or right atrial transmural pressure, ${ }^{27}$ is not affected by bilateral adrenalectomy, ${ }^{5}$ and is not abolished by beta blockade. ${ }^{19}$ It appears to be an inherent property of the myocardium whereby an acceleration in heart rate occurs proportional to the work performed. The mechanism of this acceleration is still, however, unknown.

The results of this study have confirmed in human transplant recipients the results of previous animal studies. In two studies, one under laboratory conditions $^{19}$ and the other using trained, highly motivated racing greyhounds, 20 Donald et al. showed that neither denervation nor the administration of propranolol to normal dogs caused any significant reduction in the capacity for exercise. The administration of propranolol after denervation, however, resulted in the animals either failing to complete the previously attained level of exercise in $85 \%$ of tests, with the dogs collapsing on the moving treadmill, ${ }^{19}$ or finishing races in a totally exhausted condition at walking pace. ${ }^{20}$

It is apparent from Fig. 1 and 2 that though propranolol has attenuated the heart rate response of the patients early in exercise, its effect is relatively minor. As the severity of exercise is increased after three minutes, the effect of the beta blockade is more apparent, completely abolishing the more pronounced increase in heart rate that occurs after this point during the control tests. This more pronounced increase in heart rate after approximately three minutes of the control test confirms previous reports ${ }^{712}$ and is consistent with the onset of action of endogenously released catecholamines. The ability of the denervated heart to perform anything more than mild exercise appears to be critically dependent on this release of catecholamines into the blood stream to augment cardiac output through its effect on heart rate and contractility. ${ }^{6}$

Although catecholamines also appear to be of importance in the response of the innervated heart to severe exercise, ${ }^{25}{ }^{26}$ studies on the effect of beta blockade in such subjects ${ }^{13-18}$ have only reported a reduction in exercise tolerance of a significant magnitude in one instance, ${ }^{13}$ despite significant reductions in exercise tachycardia in all studies. The innervated heart is apparently capable of appropriate haemodynamic readjustments to maintain maximal physical working capacity after beta blockade.

This investigation has confirmed earlier animal studies showing a distinct reduction in the exercise capacity of the denervated heart after the administration of a beta blocking agent. ${ }^{1920}$ Though having little effect during mild exercise, circulating catecholamines appear to be instrumental in enabling cardiac transplant recipients to retain a virtually normal capacity for exercise. Beta blockade reduces exercise performance conspicuously in such patients as evidenced in this study by a reduction in exercise endurance of $34 \%$ and an impressive endpoint to the exercise test. Beta blockers should be used with caution for the treatment of hypertension or myocardial ischaemia in patients after cardiac transplantation.

\section{References}

1 Thames MD, Kontos HA, Lower RR. Sinus arrhythmia in dogs after cardiac transplantation. Am $\mathcal{Y}$ Cardiol 1969; 24: 54-8.

2 Kontos HA, Thames MD, Lower RR. Responses to electrical and reflex autonomic stimulation in dogs with car- 
diac transplantation before and after reinnervation. $\mathcal{F}$ Thorac Cardiovasc Surg 1970; 59: 382-92.

3 Stinson EB, Griepp RB, Schroeder JS, Dong E Jr, Shumway NE. Hemodynamic observations one and two years after cardiac transplantation in man. Circulation 1972; 45: 1183-94.

4 Mason JW, Harrison DC. Electrophysiology and electropharmacology of the transplanted human heart. In: Narula OS, ed. Cardiac arrhythmias: electrophysiology, diagnosis and management. Baltimore: Williams and Wilkins, 1979: 66-81.

5 Donald DE, Shepherd JT. Response to exercise in dogs with cardiac denervation. Am F Physiol 1963; 205: 393400.

6 Pope SE, Stinson EB, Daughters GT, Schroeder JS, Ingels NB Jr, Alderman EL. Exercise response of the denervated heart in long-term cardiac transplant recipients. Am f Cardiol 1980; 46: 213-8.

7 Leachman RD, Leatherman LL, Rochelle DG, et al. Physiologic behaviour of the transplanted heart in six human recipients [Abstract]. Am $\mathcal{f}$ Cardiol 1969; 23: $123-4$.

8 Donald DE, Shepherd JT. Initial cardiovascular adjustment to exercise in dogs with chronic cardiac denervation. Am F Physiol 1964; 207: 1325-9.

9 Donald DE, Shepherd JT. Sustained capacity for exercise in dogs after complete cardiac denervation. Am $\mathcal{F}$ Cardiol 1964; 14: 853-9.

10 Patterson SW, Piper H, Starling EH. The regulation of the heart beat. F Physiol (Lond) 1914; 48: 465-513.

11 Starling EH. On the circulatory changes associated with exercise. I R Army Med Corps 1920; 34: 258-72.

12 Hallman GL, Leatherman LL, Leachman RD, et al. Function of the transplanted human heart. $\mathcal{F}$ Thorac $\mathrm{Car}$ diovasc Surg 1969; 58: 318-25.

13 Epstein SE, Robinson BF, Kahler RL, Braunwald E. Effects of beta-adrenergic blockade on the cardiac response to maximal and submaximal exercise in man. $\mathcal{F}$ Clin Invest 1965; 44: 1745-53.

14 Reybrouck T, Amery A, Billiet L. Hemodynamic response to graded exercise after chronic beta-adrenergic blockade. F Appl Physiol 1977; 42: 133-8.

15 Hansson B-G, Dymling J-F, Hedeland H, Hulthen UL. Long term treatment of moderate hypertension with the beta $_{1}$-receptor blocking agent metoprolol. 1. Effect on maximal working capacity, plasma catecholamines and renin, urinary aldosterone, blood pressure and pulse rate under basal conditions. Eur $\mathcal{F}$ Clin Pharmacol 1977; 11: $239-45$.
16 Pearson SB, Banks DC, Patrick JM. The effect of $\beta$-adrenoreceptor blockade on factors affecting exercise tolerance in normal man. Br $\mathcal{F}$ Clin Pharmacol 1979; 8: 143-8.

17 Leenen FHH, Coenen CHM, Zonderland M, Maas AHJ. Effects of cardioselective and nonselective $\beta$-blockade on dynamic exercise performance in mildly $\frac{\bar{D}}{\overline{ }}$ hypertensive men. Clin Pharmacol Ther 1980; 28: 12-21.

18 Sklar J, Johnston D, Overlie $P$, et al. The effects of a cardioselective (metoprolol) and a nonselective (propranolol) beta-adrenergic blocker on the response to. dynamic exercise in normal men. Circulation 1982; 65: 894-9.

19 Donald DE, Samueloff SL. Exercise tachycardia not due $\frac{\Omega}{\supset}$ to blood-borne agents in canine cardiac denervation. $\mathrm{Am}$ f Physiol 1966; 211: 703-11.

20 Donald DE, Ferguson DA, Milburn SE. Effect of beta- $-\dot{-}$ adrenergic receptor blockade on racing performance of $\mathcal{O}_{\infty}$ greyhounds with normal and with denervated hearts. + Circ Res 1968; 22: 127-34.

21 Bruce RA. Exercise testing of patients with coronaryheart disease. Principles and normal standards for evalu- $C$ ation. Ann Clin Res 1971; 3: 323-32.

22 McLaughlin PR, Kleiman JH, Martin RP, et al. The effect of exercise and atrial pacing on left ventricular $\oplus_{\mathscr{D}}$ volume and contractility in patients with innervated and $\stackrel{\infty}{\omega}$ denervated hearts. Circulation 1978; 58: 476-83.

23 Weiss JL, Weisfeldt ML, Mason SJ, Garrison JB, Livengood SV, Fortuin NJ. Evidence of Frank-Starling effect in man during severe semisupine exercise. Circula-O tion 1979; 59: 655-61.

24 Erickson HH, Bishop VS, Kardon MB, Horwitz LD. $\stackrel{\unrhd}{\varrho}$ Left ventricular internal diameter and cardiac function $\vec{\overrightarrow{ }}$ during exercise. 7 Appl Physiol 1971; 30: 473-8.

25 Christensen NJ, Brandsborg O. The relationship be- tween plasma catecholamine concentration and pulse rate during exercise and standing. Eur $\mathcal{F}$ Clin Invest 1973; 3: 299-306.

26 Davies CTM, Few J, Foster KG, Sargeant AJ. Plasma catecholamine concentration during dynamic exercise involving different muscle groups. Eur $\mathcal{F}$ Appl Physiol 1974; 32: 195-206.

27 Donald DE, Shepherd JT. Changes in heart rate on intravenous infusion in dogs with chronic cardiac denervation. Proc Soc Exp Biol Med 1963; 113: 315-7.

Requests for reprints to Dr R S Bexton, Department? of Cardiology, St Bartholomew's Hospital, LondonN EC1A 7BE. 